\title{
Rationalities of collaboration for language learning in a wiki
}

\author{
LINDA BRADLEY \\ Chalmers University of Technology, Department of Applied IT, Centre for \\ Language and Communication, 412 96, Göteborg, Sweden \\ (email: linda.bradley@chalmers.se) \\ BERNER LINDSTRÖM AND HANS RYSTEDT \\ University of Gothenburg, Department of Education, Box 300, 40530 Göteborg, \\ Sweden \\ (email: berner.lindstrom@gu.se; hans.rystedt@ped.gu.se)
}

\begin{abstract}
For language learning, online environments allowing for user generated content are becoming increasingly important since they offer possibilities for learners to elaborate on assignments and projects. This study investigates what wikis can do as a means to enhance group interaction, when students are encouraged to participate in constructing text and exchanging peer response. The research focus is on exploring what interaction unfolds in the wiki and how it promotes language learning, from a sociocultural perspective. This interaction is framed both by affordances in the wiki but also by what is expected from students as language learners in an English for Specific Purposes class environment. The analysis has a multilevel approach, focusing on patterns of interaction and the nature of feedback. The study shows that collaboration becomes specifically interesting from a language learning perspective. In the findings, on the student wiki pages there are numerous contributions relating to both local language and global content. Revising co-constructed text opens up possibilities for the students to evaluate existing contributions and it also provides opportunities for them to suggest constructive changes. In addition, with the environment being web based, we discuss certain benefits arising from the fact that it allows for user-generated content.
\end{abstract}

Keywords: wiki, language learning, collaboration, peer work, higher education

\section{Introduction}

The current trend in Second Learning Acquisition (SLA) is embracing the sociocultural perspective, which implies a focus on learners' participation in joint activity with others. Previously, individual cognition of language learning was more in focus (cf. Firth \& Wagner, 2007; Hampel, 2006). From a sociocultural perspective, language learning is closely connected to language use and how it is developed through participation in human social interaction mediated by cultural artifacts (Säljö, 2005). From this perspective, social and mental activities are intertwined in language activities such as speaking and writing, making the use of language and artifacts the 
origin for learning and cognition (cf. Gutiérrez, 2006; Lantolf \& Thorne, 2006; Warschauer, 2005). Accordingly, studies of learning from a sociocultural perspective imply a focus on communication when engaging in joint construction of meaning through participation in common projects. This study presents students' interactions in a project where a wiki was used as an integrated element in a language course for software engineering students in information technology. The course was targeting the type of language production that the students will encounter in their future careers. The main focus of investigation is students' written communication as displayed in the wiki environment.

Of relevance for this study is the increase in the number of online environments allowing for more user generated content in recent years. This has opened up new ways of working and learning (Alexander, 2006; Conole, 2008; Lankshear \& Knobel, 2003). Since social software has become part of the daily life of students at university, the question of integrating such technologies into learning is a key concern in education. Recent CALL discussions also revolve around questions of how to make use of these technologies, originally intended for social use and entertainment, in study contexts (Chapelle, 2007; Gillespie, 2008).

When people meet online across cultural and national borders the lingua franca is frequently English, which implies that non-native speakers of English will need to express their ideas in English. For language learning this has become a tremendous opening, giving students the opportunity to engage in various ways and with different online tools. Therefore, user modified and interactive web environments such as wikis are potentially beneficial for foreign language learning. It is thus of interest to investigate the use of such technologies and to explore possible implications for instructional design. The wiki itself holds certain affordances, i.e. options for interaction in the relationship between the participants and the tool (Gibson, 1977). The concept of affordances with wikis in relation to language learning is used in line with Lund (2008) who claims that "language learning cannot be seen as de-contextualized from the sociotechnical affordances and constraints of the wiki environment" (op. cit.: 36), which allows for the investigion of unlimited participation and collective language production. Wiki technology offers web spaces for structuring content and designing for interaction. It is based on a functionality called open editing (Leuf \& Cunningham, 2001), enabling users to add, develop, revise and refine content within a designated online space. As claimed by Godwin-Jones (2003) "wikis are intensely collaborative" and suited for groups participating in writing projects.

\section{Framing the study}

Since recent forms of textual practice are related to conditions offered by usergenerated online applications and environments, this study emanates from the notion that there are certain collaborative aspects of interest in these environments also from a language learning perspective. The interaction between users is seen as content production in relation to given peer feedback, where exchange of ideas and collaborative productivity are claimed to play a vital role for learning (Donato, 2004). This productivity and progression in student collaboration can be discussed from the pedagogical framework of multiliteracies developed by Cope and Kalantzis 
(2000), which is based on "the assumption that the human mind is embodied, situated and social" (op. cit.: 30). It states that the development of human knowledge is part of collaborative interaction. This framework holds four distinct interrelated areas, situated practice, overt instruction, critical framing, and transformed practice. It is built around the notion of the learner as an able designer for learning, which is also central to this study, where students are part of a process in change, characteristic of language learning.

\subsection{Wikis in language education}

For education, there are relatively few empirical studies where wikis have been applied as a platform for student interaction. In existing studies, the collaborative potential of the wiki concept as a writing tool is frequently assumed (cf. Arnold, Ducate \& Kost, 2009; Augar, Raitman \& Zhou, 2004; Forte \& Bruckman, 2006). Features which are stressed include the promotion of revision and tracking of drafts, together with the pedagogical challenges of an open editing space, such as the organizational issues in course management (cf. Garza \& Hern, 2006; Lamb, 2004). As far as empirical research studies of wikis in language learning are concerned, there are few studies so far discussing collaborative writing in relation to the implementation of a wiki in the pedagogical environment of language learning, which is the focus of this article.

Studies of interaction in wiki environments by Lund and Smørdal (2006) and Lund (2008), show that there is tension between individual and collective ownership. Their studies discuss the fact that students need to get used to this collective ownership when writing. They claim that collective knowledge production first starts with local content development and then moves over to a networked level, a process that needs to be designed for.

Mak and Coniam (2008) studied the use of a wiki as an online collaborative writing tool in an English as a second language programme for seventh graders to find out how students collaborate and what effects collaboration has on the finished product. Their results show that students produce a vast amount of text in the wiki environment. This text was expanded, reorganized and corrected by the students which resulted in improved coherence. However, it is concluded that for the students, peer reviewing was a new experience and something they were reluctant to engage in. Therefore, the idea of collaboration was not fully made use of by the students.

Another study by Arnold et al. (2009) shows positive results of collaboration in an undergraduate course in German as a foreign language. This study investigated the number of revisions students make on a wiki and what kinds of revision they make in relation to linguistic accuracy. In this study the participants were willing to embrace both teacher and self-initiated feedback. This study shows that students not only performed a large number of revisions of their writings, they also created higher quality texts due to teacher and peer initiated feedback. These results suggest that wikis can foster both writing skills and revision performance in linguistic accuracy.

In Kessler's (2009) study of the usage of a wiki with pre-service English as foreign language teachers, the results indicate that the students are more willing to collaborate about aspects of content rather than form in such an environment. The results 
show that even though the students are asked to highlight both content and language in their feedback, they are primarily engaged in content-based feedback and not formbased. This suggests that the lack of attention is due to the level of grammatical accuracy being acceptable for the informal context of the wiki as a writing environment.

The nature of collaboration taking place in social software such as a wiki, when used for peer learning, deserves further attention. From previous studies it is possible to see that students are active contributors when writing, although they may not always be so familiar with the online environment. However, in these studies there is a variation in the nature of the collaboration taking place from a language learning perspective, not only related to linguistic accuracy but also to content and structure, together with the development of reviewing skills, which calls for further attention. Therefore, the character of student interaction and the nature of the collaboration is worth further investigation.

\subsection{Collaborating in user generated online environments}

Within the concept of collaborative learning it is assumed that there is an added value in diverse perspectives that individuals can bring to a group process (Dillenbourg, 1999; Donato, 2004). One of the basic shared assumptions is related to the distinction between co-operation and collaboration. The concept of co-operation can be explained as individuals working autonomously in the presence of others, where the individually constructed contributions are compiled to make a unified whole, at a later stage (Donato, 2004). Collaboration, on the other hand, takes place when individual contributions to group reasoning enable the group to come to new or changed insights regarded as impossible to gain by the individuals on their own (Donato, 2004; Cope \& Kalantzis, 2000). Thus, there is a shift from individual mastering in isolation to learning through participating in a collective activity (Sotillo, 2002). In the nature of what a wiki offers lies the idea of letting its users revise joint text, which implies that it is in a "constant state of potential collaborative change" (Kessler, 2009). Accordingly, there are strong arguments supporting the idea that wiki technology could support collaboration and offer new possibilities for language learning.

In collaborative language learning, interaction is coupled with revision and feedback among participants, a means of identifying strengths and weaknesses in order to improve performance and develop language skills (Dippold, 2009). The type of feedback commonly found in language learning is related to both formalist and functionalist frameworks, which implies that both language system accuracy and the communicative context are in focus when giving feedback (Hyland \& Hyland, 2006). This is what Liu and Sadler (2003) define as local feedback, i.e. form comments at word spelling and grammar level, and global feedback, i.e. content comments about the development and organization of writing.

Previous research in feedback is inconclusive regarding the best ways to provide feedback, for example, whether it should be corrective or point out problematic areas (Hyland \& Hyland, 2006). Previously, language learning feedback was primarily concerned with error correction by the teacher and not so much the writing process (Hyland \& Hyland, 2006; Lee, 2008). Over the past years, the traditional role of the teacher giving feedback has been replaced by alternative ways, one of them being 
peer response. Not least through the use of new media, there has been a shift implying that learners are more engaged in peer work (Liu \& Sadler, 2003). Thus, the roles of who is responsible for giving feedback have been altered, making peers accountable for taking charge, giving response to each other. It is claimed that peer feedback can generate ideas and raise aspects of the content that the teachers cannot (Rollinson, 2005).

In this way, Rollinson claims that teacher and peer feedback can be considered complementary, since teachers often provide precise language comments where peers may give content based feedback. In addition, peer commenting has been shown to raise learners' awareness of their own strengths and weaknesses, which will encourage collaborative learning, providing them with more control and autonomy (Hyland \& Hyland, 2006).

\subsection{Research questions}

The purpose of this study is to examine the written interaction that unfolds when a wiki is used as an integrated element in an English for Specific Purposes (ESP) course in an engineering programme. The students' interactions on the wiki is investigated by scrutinizing their participation and the written contributions they make when they are offered the opportunity to use a wiki as a platform for the production of texts and discussions. The wiki allows for different kinds of contribution which may be productive in various ways from a language learning perspective. When students are to be engaged in joint construction of text, revising and commenting are central components. Of central interest in the study is how the student's various contributions constitute different forms of interaction and what these may imply for the student's language learning process.

Thus, the following research questions are addressed:

1) In an environment allowing for user-generated content, what interactive work are students engaged in?

2) What is the nature of the interaction regarding student participation as far as co-operation and collaboration is concerned?

3) What is the potential of wikis for language learning?

\section{Research design and methods}

This is a design-based case study, investigating student wiki interaction. Framing the data, first the context around it will be presented. Then, the analysis and the principles of categorizing the logged student wiki pages will be described, together with the reasoning behind the chosen excerpts of student interaction presented in the results.

\subsection{Context}

The participants in this study were Swedish software engineering students within computer science, taking a seven-week advanced ESP course in Spring 2008. The study is part of an ongoing design-based (cf. Brown, 1992) wiki project at the university in question and the coursework from 2008 comprises the body of the analysed empirical data. 
Initially, the students were asked to form groups of two or three for interaction on the wiki. All in all there were 56 students in 27 groups. They were instructed to join Wikispaces, register for the course wiki and create a group web page. They were asked to name their page with their own names and link it to the navigation bar on the wiki start page to make it visible for all users of the space. There were five students who had used a wiki previously for collaboration at university and one who had used a wiki at work. Since the wiki was entirely open, it was possible for both members and external readers to take part in the posted information; however, only members of the wiki, i.e. the students and teachers could write on the pages. This arrangement enabled the participants to see the user names of collaborating members at the same time as the wiki was open for external visitors.

For the students, the course aims were expressed in terms of being engaged in language learning for professional development. This implied augmenting and refining existing competences with the aim of targeting vocational requirements. In addition to learning professional writing, the agenda included discussions, negotiation and argumentation for professional team processes. Furthermore, for the students the wiki was described as an online space that would give them the opportunity to extend their language learning environment outside the classroom and where they could practise their linguistic and communicative competence together with fellow students. The explicit focus on active participation on the wiki was aimed at placing the responsibility with the students themselves.

The three teachers involved only participated in the wiki as administrators, allowing access for the students to become members of the wiki, moderating instructions on the start page and giving feedback on the student web pages after the first assignment. They were not part of the development of the content of the discussions. In addition, the wiki assignments performed by the students were not graded.

The course was built around thematic English course modules of relevance identified for future software engineers and the wiki assignments were connected to these modules. All in all there were four explicit student assignments on the wiki. There were deadlines for each assignment, even though the students were free to continue with further wiki interaction afterwards. Table 1 shows the contents of the course modules which have a related wiki assignment.

Module one, the introductory theme of the course, dealt with the transformation of styles from more informal language into formal. The wiki served as a platform where the students could exchange ideas and start their discussions and writing process around 'today's culture', which continued in the weekly classes at university. The second module dealt with another central theme, with two wiki assignments: argumentation and speech rhetoric, and referencing in academic and technical reports. In this module, students were asked to write a joint text debating the issue of using editable online references in technical reports. They were also requested to find another group to give feedback to. In this way, the students could compare their own ideas with those of other groups and at the same time focus on giving feedback. The third course module addressed the process of writing critiques on topical issues, drawing conclusions from given source material. The fourth and final course module, which did not have a corresponding wiki assignment, was integrated with the ongoing bachelor's projects, introducing the format 'extended abstract' to be 
Table 1 Layout of the modules that include the four wiki assignments in the ESP course

\begin{tabular}{ll}
\hline \hline Course module content & Wiki assignment content \\
\hline \hline $\begin{array}{c}\text { Transformation of styles, } \\
\text { informal-formal language }\end{array}$ & $\begin{array}{c}\text { "Snacking of society" theme, introductory discussions, } \\
\text { based on two online popular science articles on } \\
\text { today's culture } \\
\text { - teacher feedback } \\
\text { "Negotiation of tasks for speech" theme }\end{array}$ \\
$\begin{array}{c}\text { Argumentation and rhetoric, } \\
\text { analyses of rhetoric speech }\end{array}$ & $\begin{array}{l}\text { "Wikipedia as reference" theme, using editable web } \\
\text { Referencing in academic and } \\
\text { technical reports }\end{array}$ \\
$\begin{array}{c}\text { resources as references, pros and cons, finding new } \\
\text { articles on the theme } \\
\text { Critique writing, summarizing } \\
\text { and commenting }\end{array}$ & "Public surveillance" theme, discussions related to \\
& critique writing \\
\hline \hline
\end{tabular}

presented in English. All course modules involved practising skills in speech and writing summaries or argumentative texts based on a number of IT-related articles dealing with academic writing.

Instructions for the four wiki assignments were posted on the wiki start page gradually by the teachers and they were intentionally kept brief. In this way the contents of the interaction would not be affected by the assignment instruction. Quote 1 is the instruction for the first assignment on the wiki. The other wiki assignments were also given in the same brief fashion on the wiki start page:

Discuss the "Snacking of society" - theme from the texts in the first session. The discussion should be done in your peer group and result in a joint text of approximately 300 words. Take turns in writing on your peer group's page by choosing "Edit this page" and then saving your new version.

Quote 1. Instruction for the first wiki assignment.

The students worked with their text on their group web page, updating and modifying it until a specified deadline. There was no specific request to pay attention to content or language in the instructions. However, in class seminars stylistic variation was brought up, targeting what characterizes formal writing, subsequently something students had in mind when writing. The instructions were simply "take turns in writing". This implied that the students were meant to create their joint text by taking turns editing their wiki page and saving updated versions of their assignment.

\subsection{Data and analysis}

The wiki was investigated after the termination of the course, where 25 student wiki pages were scrutinized. In total there were 54 students in this study, comprising 21 groups of two and four groups of three. In addition, there were two students who joined the course late and decided to work individually on the wiki. Since the scope 
of this investigation was scrutinizing peer work, these two students' wiki pages were excluded from the investigated data.

The interaction was categorized into the forms of interaction that the groups were engaged in throughout their entire wiki participation, from the first to the last posting. The reasoning behind not having a continuous investigation of the wiki pages during the course progression was linked to the idea of taking the student perspective. The students were supposed to be able to design their own interaction on their group wiki pages without interference from the teachers and researchers. Investigating the wiki in its entirety after the termination of the course thus offered possibilities to see what interaction there had been on the part of students and how it had developed throughout the seven weeks of the course.

For the analysis of the student interaction on the wiki, archived versions of student peer group wiki pages were investigated, as suggested by Arnold et al. (2009), who made comparisons between archived versions of wiki web pages in their study of students in an advanced German course. In this way it is possible to follow what alterations were made, when they were made and by whom. In a wiki, the version handling is easily accessible for the users, being displayed as one of the top links on the web pages. It displays date, time and authors of each version. The changes are shown by means of colour coding.

Concerning ethical issues, all students gave their consent to their postings being published for research purposes. For the sake of anonymity, all student names and usernames have been changed.

\section{Results}

The results of this study show the student contributions found in the wiki, distinguishing different types of posted interaction. These contributions range from no visible interaction among group members on the wiki to a high level of collaborative text alterations. Apart from posting a piece of individual text, the first visible peer work is seen in students taking turns posting text on their group web page, cooperating around a joint theme. Here, the students appear more as individual contributors, though connected to a peer group. Another activity is when the postings are negotiated and discussed so that existing text is updated with new content. This shows a higher degree of interaction where contributions imply more collaborative efforts. Yet another collaborative effort seen in the wiki is giving feedback within peer groups as well as between groups. The comments are of various kinds, from editing text and saving the new version to making explicit comments, motivating a specific suggestion. The excerpts on the following pages are typical instances of the student contributions found in the wiki, serving as examples of what the interaction looks like.

Out of the 25 existing groups, five groups fall into the category of posting a full piece of text not showing any co-operation or collaboration on the wiki. Another five groups are primarily co-operating on the wiki. This implies that the group members are acting as individuals contributing to their joint texts on their web page. The largest category, however, is the one related to collaboration. There are 15 groups engaged in adding and refining ideas in joint construction together with peers. 
Regarding feedback between groups, there are 19 active groups engaged in giving feedback to another group. When scrutinizing the revisions of text on the student wiki pages, the number of times the group web pages are updated, i.e. editing and saving text on each group web page, range from eight updates to 37 . The average number of updates is 19 . Concerning the relation between the number of group participants and the nature of postings, there is no difference between the groups with three participants and those with two.

The excerpts displayed are representative of student text production from the different categories found in the wiki. There is a progression from little to more visible interaction through the wiki version handling. The colour coding of deleted and inserted text unveils the nature of student contributions on the wiki, posted text being green (light grey in this paper) and deleted, red (dark grey in this paper). The categorization will be elaborated further in this section, where excerpts will be scrutinized and discussed.

\subsection{Posting text and co-operating around a joint theme}

When posting a full piece of text, there is no visible sign of interaction. This happens when a piece of writing is posted by one author but is untouched by any other student in the peer group. Turning to the version handling in the wiki, it is possible to see a full text of the entire assignment being saved on one occasion, since the text is entirely green (light grey). Here the text only displays the finished product and not the writing process. However, posting text does not automatically mean that the piece of writing has not been elaborated on outside of the wiki, even though the text has been produced in one edit. Of the 25 groups, five can be placed in the category of posting text, having no visible co-operation or collaboration on their wiki web page, as shown in Excerpt 1 from the introductory theme.

\section{Excerpt 1}

The first text we read was named snack lash and is about how movies and games tend to get longer. This is also true for TV-series, but recently the viewers also need to see all episodes to follow the story. One contributing reason might be that people download series from the Internet. By people doing this, they make advertising for the TV-series by talking about them and this could make more peoples interested to see the TV-series. Now a days the viewers or listeners or traditional media like TV and radio aren't bound to times like before, today it is possible to choose when one wants to watch simply by downloading, streaming and buy per pay-per-view.

The next step moving towards more visible interaction on the wiki is co-operation, i.e. students producing pieces of text for their peer group acting as individuals working autonomously but in the presence of others. This type of activity is of a co-operative nature, since the text is processed by individuals working parallel with a joint project (Dillenbourg, 1999; Donato, 2004). There are rarely any author comments between the versions written, just updates of newer versions of text. For the students engaged in this activity, sections of postings are attributed to separate individuals. The following two excerpts are representative of co-operation, both being from the 'Wikipedia as reference' theme. In Excerpt 2, two students in a group take turns writing on the assignment. Going to the version handling on the wiki page of the particular text version when this 
new text was posted, it is possible to see a change in colour from white, implying existing text, to green (light grey), implying new text:

\section{Excerpt 2}

Furthermore the text presents an interesting parallel to how indifferent the use of Wikipedia actually is to using books - that the way people back in the preinternet era memorized outlined quotes from books does not differ that much from how young students these days go to wikipedia and quickly read up on a subject. ... Another thing worth mentioning is that the few errors that exist on Wikipedia get quickly corrected because of the number of users and certain articles which attract "vandal editors" are protected from interference. If you compare the time it takes to correct an error in a book with correcting an error in Wikipedia, the result is clearly on Wikipedias side but it of course it also depends on the correctors understanding of the topic.

To sum it up we think that Wikipedia can be used as an introduction to a topic, but if you want reliable sources you should stick to the libraries and such. But we also think that it won't be long before Wikipedia will be classified as a reliable source like for example Britannica (which it already has beaten in a study).

In addition to posting more text on the current assigned topic, the second peer student has also deleted the three dots, leaving a red trace (dark grey) in the version produced by the first peer student, for the peer to continue. Even though the two students may have other means of communicating, such as chatting or meeting in person, the only interaction visible on the wiki is that of taking turns at writing independently on the same topic. By the deadline, the text will consequently have been built by two separate contributors. There is little focus on form in this activity and more on producing content for the joint topic.

In the next example, Excerpt 3, also illustrating co-operation, the second student picking up the topic has marked the presence of this being a peer project by embracing his partner in the text by posting "We believe". Excerpt 3 shows that cooperating implies contributors having an idea of joint production, even though joint revision in altering common text is not applied.

\section{Excerpt 3}

People that are looking for IT-related subjects will probably find wiki's, such as Wikipedia very useful. Since the information about IT is so computer-based, most of the experts in those subjects will have access to internet and Wikipedia, so many experts can change the information. When looking for information about some subject further away from computer you might find it being less correct since less experts can contribute to the pages.

[...] We believe that it depends on the field, some fields are more subjective than others. For example, whether or not electromagnetical fields causes cancer is a subject that is somewhat controversial and there are not yet clear evidence for it. Because of this, different authors may have radically different views on the subject and therefore their articles may be more an expression of their personal opinion than an objective truth. 
From what is seen in the version handling of the wiki postings, when co-operating in writing peers read the previous already-posted text and add more on the topic. In some instances there has been a clear division of work, when for instance one of the students clearly takes a stand for and the other student takes a stand against a specific topic. Thus, even though participants were working on parallel tracks, in cooperation there is a certain amount of teamwork. Out of the 25 groups, co-operation was the dominant form of interaction in five groups, even though there were some traces of collaboration in some of their assignments.

\title{
4.2 Collaborating
}

Moving over to collaboration, this implies more comprehensive and refined interaction. Here, students are engaged in writing a joint text but also taking part in each other's ideas, evaluating and refining them. They then produce a piece of text each by taking turns in contributing to the writing process but also going back, revising existing content. Students add their ideas to their group's text by editing previous versions of the text. Now there is no longer any clear division between the separate group members of the web page, but the writers become owners of the whole text together. When turning to the revisions in the wiki version handling, it is possible to see that updates are intertwined and previously posted text is elaborated on by the different users.

Following a collaborating group from the initiation of a topic to the deadline, there is a mix of intertwined posted text elaborated by all its group members. An example of collaboration can be seen in Excerpt 4, where two students take turns writing the first wiki assignment in ten revisions. In the first revision, one of the peers contributes with a paragraph of text introducing the topic. In the second revision the same contributor makes a few changes to his original text prior to leaving it for the other group member to take over. The green (light grey) is inserted new text and the red (dark grey) is deleted text:

\section{Excerpt 4}

\begin{abstract}
After reading both of the articles about how new technology and media effects affects our lifes lives and society, we started to discuss whether we agree or not. We both agreed that movies and tv-shows are getting longer, and there are a whole lot of more tv-shows to choose between. We discussed why movies, tv-showes and music influence and takes take the large amount of time of our spare time as it does, and came to the conclusion that the easy acces access has alot a lot to do with it. Because almost all movie, movies, tvshows and music is are easy to download, we can watch our movies or tv-shows, or listen to our music whenever we want, wherever we want.
\end{abstract}

In the excerpt, there are changes made related to spelling and grammar, e.g. 'effects' changed to 'affects', 'lifes' to 'lives' and 'tv-shows and music is' to 'tv-shows and music are'.

From the third to the eighth revision, the two students contribute to their common text by adding new text and making clarifications of already posted ideas. The last two revisions are made before the deadline, where the two students contribute with 
one revision each of a more proof-reading nature. Excerpt 5 shows the ninth, the second last, contribution:

\section{Excerpt 5}

After reading both of the articles about how new technology and media affects our lives and society, we started to discuss whether we agree or not. We both agreed that movies and tvshows are getting longer, and there are a whole lot of more tv-shows to choose between. We discussed why movies, tv-showes and music influence a nd and why it take the large amount of time of our spare time as it does, and came to the conclusion that the easy access has a lot to do with it. Because almost all movies, tv-shows and music are easy to download, we can watch our movies or tv-shows, or listen to our music whenever we want, wherever we want.

This might lead towards all spare time we got is dedicated towards watching movies or tvshows or listening to music because of the easy access to download the video or audio. audio and video. If you go back 10 years it was a lot different. At home when a specific tv-show was on tv all gather in the sofa to watch the show. show together. In some way it was a kind of family quality time. Nowadays everything is stressed up, the list it's different. Not only the lists of movies and tv-shows are a lot longer but there are still only 24 hours. also the playtime. People watches movis or tv-show watch movies or tv-shows if they have time when it airs on tv, or they download it and whats watch it when they have some time to spare. sparetime.

At the same time this mobility snacking as good as it seems to be all things have a downside. I'm We are all up for the mobility but why then do you sometimes feel that the best thing you have done the all day is to turn of your cellphone? I guess the flow of information from internet, tv-shows and games just gets to much sometimes.

From the initial first paragraph of the assignment, the text has been extended by two more paragraphs. In Excerpt 5, the group has tried to make improvements in the text by extending and altering various phrases. Also, the text has been embraced to become a joint effort in changing 'I'm all up for the mobility' to 'We are all up for the mobility'.

When collaborating, students take steps to improve their text, even though not all errors are always corrected. An example of this can be seen in the second paragraph in Excerpt 5 where the erroneous phrase 'when it airs on tv', published in the eighth revision, is untouched by the two peers throughout the rest of the revisions. This illustrates that the writing process is an ongoing process that does not immediately catch all language mistakes. However, by the deadline a final version was presented, where clarifications and corrections were made to the group's best joint efforts.

When analysing the 25 peer groups' archived versions of their wiki pages, it is possible to see that 15 groups were primarily engaged in collaboration, i.e. adding, revising and refining ideas in joint construction of text together with their peer. In their work, there are elements of local, language aspects as well as global, content aspects in the text revisions.

Within peer collaboration, the text can be altered without any additional comment in the immediate vicinity of the posted text (as seen in Excerpts 4 and 5). However, peers quite often address each other with explicit meta-comments next to the posted text, e.g. requesting peers to continue writing on their joint text: "någon kan fortsätta här/ Mattias" [one of you can continue here/Mattias]. Frequently, these author comments between text versions are either removed further along the writing process, or kept as part of the text saved for the deadline to point out contributions by specific writers.

Excerpt 6 is another example of meta-commenting, from a group in the process of writing their wiki text in the introductory module on 'today's culture'. The first 
student makes a statement asking for the peer's view and the second student replies, keeping up the dialogue:

\section{Excerpt 6}

make today. Because that I think that altough many movies today are superficial but thats not because they don't have enough time but because most movies are bad. It's possible to make deep movies if you have the talent. What do you think?

\section{Since my intrest in movie are not the same as yours I do not agree, I love movies where} you do not need to think very much, like superficial movies.

Consequently, the first student is inviting the second student into a discussion, to share and develop understanding, which may contribute to the ideas in their writing process. This type of collaborative interaction differs from co-operation since in collaboration the students refer back to previous discussion about the existing content, to refine their own understanding.

Looking further into the nature of revision changes found in the texts, Excerpt 7 from the introductory module shows how students collaborate to improve their text style, which was part of that assignment. The excerpt is the last part of a longer text preceded by four versions saved on this peer group's web page. The text has been updated by one of the three peers of the group in question. The students have been altering and adding ideas throughout their entire writing process, taking turns, becoming joint owners of the whole text. Here, the students are engaged in formalist as well as functionalist work, implying that both language system accuracy and the communicative context are in focus when making alterations (Hyland \& Hyland, 2006). However, there are no additional comments in the text clarifying the alterations made. The text has just been changed. The green (light grey) is inserted new text and the red (dark grey) is deleted text:

\section{Excerpt 7}

However as the article hints at at, the distribution of todays media has changed. Even though there are more shows and movies available nowadays, they can also more easily reach are now being distributed to a bigger audience. This is especially true for English shows and even if your show only interests a small group of people, it can still be successful.

Another really nice thing with "snacking" is the possibility to enjoy your favorite show any time you feel like it. Even if it's at 3am you will have access to it. Regarding the trend to chain episodes so that you are forced to watch all of them to be able to follow the show, I we think that's a good thing because it adds depth to the episode since they can focus more on creating a deep and intense storyline.

In Excerpt 7, the student has altered his peers' version by adding a comma after 'at', and making a modification of the sentence, deleting part of a phrase and adding 'are now being distributed to'. Furthermore, 'Even if it's 3am' has been altered to 'Even at 3am'. In addition, the excerpt shows that the peer student has turned personal expressions posted in the previous version into a joint concern by deleting the personal expression, modifying the text by removing the personal pronoun from "I think that's a good thing" to "we think that's a good thing". The style and communicative approach has changed from being more informal and characterised by the views of one person, to representing a more general perspective which the group members have contributed to. 
Thus, modification of text elements by developing the contents may alter the genre, transferring it from an informal style to a more formal one.

Concerning the specific feedback assignments displayed in the wiki, the teachers gave feedback for the first time after the deadline for the first assignment. The teachers then made use of the version handling of the wiki to let the students see comment suggestions in colour. Since text marked in green (light grey in this article) implies inserted new text and text marked in red (dark grey in this article), deleted text, the alterations were easy to follow.

By requesting the students to go to the version handling on their web page and to the teacher's updated text version, it was possible to see the specific teacher's comments in colour. This is an example of the last part of the teacher comment on a student group's web page, where the teacher asks the group to go to the version handling, called 'history' in Wikispaces, to get a better overview of the comments given: "... see comments above in text. You can go to 'history' to see the changes in colour./Gitte". The version handling of the wiki was also used in the analysis of the empirical data as described in section 3.2.

After the deadline of the second assignment it was the students' turn to give feedback, one peer group to another. The students were instructed to choose another group on the wiki to give feedback to. In order for the students to find another group that had not yet received feedback by another peer group, they had to go through a number of web pages. Feedback procedures were practised in a workshop in class in the first course module. In addition, students could follow the teachers' method of giving feedback on the wiki after the first assignment, by editing a page and saving the comments in connection with the written text.

Turning to the peer feedback on the group web pages, when students respond to each other there is a combination of global, content-related and local, languagerelated comments (Liu \& Sadler, 2003). In Excerpt 8, one peer group gives feedback to another group, offering both global suggestions after 'Comment' and local suggestions in the form of direct alterations in the text:

\section{Excerpt 8}

What role should a wiki play in authentic research?

One of the most interesting and important places on the Internet is probably Wikipedia. Wikipedia is a wiki, so anyone can read and edit the material, and hopefully make it better and more correct. Comment. Perhaps get a better explanation of "wiki".

Wikipedia is a good way to get information about a great variety of subjects. Wikipedia is especially good to find information about new topics that takes forever and ever to get printed in books. If you want to get some brief information about a topic then Wikipedia is a perfect way to start, here you can choose to read about details or simply get a summary of the topic.

Wikis like Wikipedia are often criticized just for the same reason that makes them popular and filled with all kinds of knowledge, the possibility for anyone to edit. Because the wiki is a collaborative work there is no single author that can be responsible for the contents of the article and there is always the possibility that someone has posted inaccurate information, but this is seldom the case. Comment: How do you know that it is seldom the case?

To make Wikipedia more reliable they have a lot of policys policies that regulates how and what should be written in the articles. One of the importants is one that says most important things is that no original work should be written, every fact should be verifiable. This makes it possible for the reader to check the sources and verify the content. So if you want to quickly get information about a topic topic, then you can go to Wikipedia and read about it and then it. After that read the references to get a good starting point for further information. Comment: Weird and long sentences in this phrase.

We think that Wikipedia is a great way to use critical evaluation, one of the best actually. Since everything is written by random people one must always think about the content and read it with a critical eye. When you use Wikipedia in an article or report you should probably try to use the Wikipedia article's sources and not the article itself as a source, but when the original source is hard to find, like an old book that exists in just a few copies, you should be allowed to use Wikipedia as the source, source. (Comment: This is not a good argument for being allowed to use Wikipedia!) If you do use Wikipedia as a source it is important that you use some common sense and look at the facts critically and don't forget to specify exactly which revision of the article you use. 
Global feedback mainly concerns whether arguments raised are feasible and well communicated. These comments involve more than just editing a single word or sentence, for example, what is pointed out after each 'Comment' in Excerpt 8. Local linguistic comments are given by making changes directly in the text by deleting and adding new content, as seen in Excerpt 8 when, for example, changing 'policys' to 'policies'.

Frequently, reviewing suggestions are marked with brackets or a deviating colour together with giving a remark as seen in Excerpt 9. In this example the revising group cannot target the exact reason for suggesting an alternative pronoun, "who", other than it "feels more correct". This is an example of the difference between peer feedback and teacher feedback, the latter being more precise in putting words to linguistic explanations.

\section{Excerpt 9}

The main advantage of editable resourses like wikis is the flexibility and its power of spreading information. Education institutes can easily use wikis to hold distance courses for those that (who) ( Who" feels more correct, but "That" works) dont have the ability to attend school at a normal fashion. For example

For the peer feedback, part of the second wiki assignment, students were requested to find another group in the navigation list on the wiki and provide comments. The task was open, though all groups had already received teacher feedback so the groups could mimic the pattern of addressing other groups given by the teachers. There were six groups that did not engage in this activity of giving feedback to another group, even though they may have been given feedback by one of the 19 active groups. This explains why not all 25 groups are found in table 2 . The following distribution was found in the wiki from 2008:

Table 2 Feedback found in the 19 groups that were given feedback after the second assignment

Type of feedback

End comments only

Comments in text only

End comment + comments in text
Number of comments in groups

4
2
13

2

13

Table 2 shows that the most frequent type of feedback was giving peer comments at the end of the assignment on the group web pages, an activity which all groups but two were engaged in. When investigating the nineteen given end-comments, on seven group web pages, they were global, non-revision-oriented overall comments, as shown in Quote 2.

Good explanation of what a wiki is at the beginning. Good structure and nice flow thorugh the text. Nothing to complain about.

This type of general comment is an "easy way out" of putting little effort into peer commenting, which will be unlikely to contribute to much improvement for the receivers. 
However, on twelve group web pages the comments were global, though more targeted, as seen in Quote 3, giving specific recommendations or questioning the interpretation of a concept.

Comment:

Short and concise description of the pros and cons of wikipedia. Maybe you could have written about some additional sources and compared them against Wikipedia.

Some confusion regarding the words scientific and "scientific". Do you mean scientific pages on Wikipedia or other sources of scientific articles?

Receiving this type of comment is likely to contribute to the language learning process, even though it may be difficult to make changes in the text.

Apart from giving end comments, a majority of the student groups also gave comments in the text, as shown in table 2. These in-text comments included both local, language oriented, and global, more content-oriented comments.

\section{Discussion and conclusion}

Software engineering students using a wiki as an interactive tool within the framework of language learning were engaged in peer work in a number of ways. Even though the students were encouraged to take turns editing and modifying their assignments jointly on their web page, this work was carried out in quite different ways, which is demonstrated by the findings. Turning to research question (1) regarding what interactive work students are engaged in, the version handling of the wiki gives a picture of how the students have been contributing. In the analysis of the text versions produced, some of the contributions show more collaborative effort and some less. This study shows that the nature of the contributions has implications for language learning as far as the process of practising writing skills and the ways of giving peer response are concerned. The collaborating groups produced more versions of revised text, with a higher number of edits in their assignments.

The type of contribution with the least visible interaction is a posted piece of text where further interaction between group members is not visible. Since there is no way of seeing how much of the writing process was applied in such posted pieces of text, it is not possible to determine whether the students were engaged in collaborative work at all. Instead, it could be one person writing the entire piece of text. The wiki functionality only allows one person at a time to edit the same text.

Concerning question (2) about the nature of the co-operative and collaborative work students are engaged in, co-operation implied joint individual posting to a common theme. Here, the students expressed their views in a dialogic mode, taking turns at posting ideas. Yet another type of contribution was through collaboration, where students produced joint texts and then made alterations and additions. For this latter type, collaborative writing, a wiki is particularly suitable, since it is possible to go straight into the text and edit at a targeted position. Also, when turning to the version handling in the wiki, the colour coding can be helpful as support to see what another writer or commenter has posted. 
As stated by Donato (2004), "interaction does not categorically mean collaboration", though response work is tightly connected to collaboration around editing and revising. When the students were asked to provide constructive comments to each other, there was a variation in the feedback given. Even though the students were not requested to target their response in any specific way, it turned out that some response was more linguistically oriented whereas other was more focused on content. Quite often students applied a combination of both approaches when being responsive to fellow students. However, the findings show that there are more linguistic comments. This indicates that students were probably aware of the fact that both formalist and functionalist competences deserved their attention in language learning. The data also shows that the given feedback is more or less explicit, targeting a range of relevant issues concerning both global and local areas of the text. Such feedback, as offered by the peers, may play an essential role in language learning, as suggested by, for example, Hyland and Hyland (2006). The fact that it is an electronic environment enhances the quality and immediacy of the feedback, inviting the students to go straight into the text, which facilitates more commenting on a more detailed level. A process that allows more revisions to improve text production is something that has a strong potential from a language learning perspective.

To question (3) about the potential of wikis for language learning, this study shows that from a language learning perspective collaborative work becomes particularly interesting. Revising a co-constructed text opens up possibilities for evaluating existing contributions that have been elaborated on previously and it also facilitates critical evaluation and suggestions for constructive changes. In addition, with the environment being web based, it facilitates the writing process, allowing users to write whenever they are inspired. A majority of the groups were in fact engaged in collaboration, which can be explained by the collaborative nature of the wiki technology, inviting members to contribute in a simple way. Even though it is possible for others to supervise the interaction on the wiki, and despite the fact that all editing is logged, the wiki is being used as a collaborative platform by most groups. This implies that the students are prepared to accept the fact that they might be watched, in exchange for the benefits of working with their joint assignments.

The fact that the content of the assignments was not controlled by the teachers, allowed the students to take command over the design of their own web pages. The teachers' assignment instructions were intentionally brief, giving students the opportunity to develop the content of their texts themselves. This is also practised by Kessler (2009) who points to the advantages of allowing for "observation of student behaviour without undue influence from the prompt" (op. cit.: 83). The students should be empowered to make their own design decisions. Since the wiki assignments were part of the compulsory course tasks, there was a large amount of activity on the part of the students.

The framework of multiliteracies (Cope \& Kalantzis, 2000), which is based on four components of pedagogy: situated practice, overt instruction, critical framing and transformed practice, offers a deepened perspective on the implications of collaborative work. It is based on the fact that motivation is a key factor in making persons interested in learning. The framework has its starting point in the situated practice and related to this article, the wiki as technology caters for a motivating space creating an interest for the learners. The next component, overt instruction, is 
the collaborative efforts in the form of active interventions between teachers and students, within and between peer groups. It is the experiences and activities within the learner community that facilitates the conscious awareness of what is being learned. In the wiki it is the interactive work that the students are engaged in, in discussing and refining their language. The third component, critical framing, relates to the fact that the students can stand back and view what they have learned in a critical way. Contributing to the joint wiki page implies both being creative and, at the same time, questioning other people's ideas. To make this possible, it requires that the students have gained the necessary personal and theoretical distance from what they have learned and that they have framed their growing mastery. The final component, transformed practice, implies that students have become reflective. They can now show that they are able to implement understanding from overt instruction and critical framing to apply and revise what they have learned.

Finally, a key issue for students of higher education is how learning elements of a course are tied to course objectives and assessment. In this study, students were recommended to interact in the wiki as a means of enhancing their communicative and linguistic capability within the framework of an ESP course. For this category of students who are digital natives (Prensky, 2005), this implies not only that they are used to adopting the new area of literacy, but also the way of learning that goes with it, which is more task oriented and experiential (Conole, 2008). In a language learning project using social software, this study shows that students will try to interpret what is expected of them. However, Lamb (2004) claims that a wiki will work most effectively if students can have control over the process of posting and that authority "undermines the effectiveness of the tool". This statement is a challenge to implement in a language learning context. When finding ways to combine the language learning situation with the web based environment of social software it will be possible to promote collaborative forms of interaction and reach what Cope and Kalantzis (2000) call a transformed practice.

\section{References}

Alexander, B. (2006) Web 2.0: A new wave of innovation for teaching and learning? Educause review, 41(2): 32-44.

Arnold, N., Ducate, L. and Kost, C. (2009) Collaborative writing in wikis. In: Lomicka, L. and Lord, G. (eds.) The next generation: Social networking and online collaboration in foreign language learning. CALICO Monograph Series, 8: 115-144.

Augar, N., Raitman, R. and Zhou, W. (2004) Teaching and learning online with wikis. ASCILITE, 2004. http://www.ascilite.org.au/conferences/perth04/procs/augar.html

Brown, A. L. (1992) Design Experiments: Theoretical and Methodological Challenges in Creating Complex Interventions in Classroom Settings. The Journal of the Learning Sciences, 2(2): 141-178.

Chapelle, C. (2007) Technology and second language acquisition. Annual Review of Applied Linguistics, 27: 98-114.

Conole, G. (2008) Listening to the learner voice: The ever changing landscape of technology use for language students. ReCALL, 20(2): 124-140.

Cope, B. and Kalantzis, M. (2000) Multiliteracies: Literacy Learning and the Design of Social Futures. New York: Routledge.

Dillenbourg, P. (1999) What do you mean by collaborative learning? In: Dillenbourg, P. (ed.) Collaborative learning: Cognitive and computational approaches. Amsterdam: Pergamon, 1-19. 
Dippold, D. (2009) Peer Feedback Through Blogs: Student and teacher perceptions in an advanced German class. ReCALL, 21(1): 18-36.

Donato, R. (2004) Aspects of collaboration in pedagogical discourse. Annual Review of Applied Linguistics, 24: 284-302.

Firth, A. and Wagner, J. (2007) Second/Foreign Language Learning as a Social Accomplishment: Elaborations on a Reconceptualized SLA. The Modern Language Journal, 91: 800-819.

Forte, A. and Bruckman, A. (2006) From Wikipedia to the Classroom: Exploring Online Publication and Learning. Paper presented at the International Conference of the Learning Sciences, Bloomington, IN.

Garza, S. L. and Hern, T. (2006) WikiAsACollaborativeWritingTool. http://critical. tamucc.edu/wiki/WikiArticle/WikiAsACollaborativeWritingTool

Gibson, J. J. (1977) The theory of affordances. In: Shaw, R. E. and Bransford, J. (eds.) Perceiving, acting, and knowing. Hillsdale, NJ: Lawrence Erlbaum Associates.

Gillespie, J. (2008) Editorial: Mastering Multimedia: Teaching Languages Through Technology. ReCALL, 20(2): 121-123.

Godwin-Jones, R. (2003) Emerging technologies: Blogs and wikis: Environments for online collaboration. Language Learning and Technology, 7(2): 12-16.

Gutiérrez, G. A. (2006) Sociocultural theory and its application to CALL: A study of the computer and its relevance as a mediational tool in the process of collaborative activity. ReCALL, 18(2): 230-251.

Hampel, R. (2006) Rethinking task design for the digital age: A framework for language teaching and learning in a synchronous online environment. ReCALL, 18(1): 105-121.

Hyland, F. and Hyland, K. (2006) State of the art article: Feedback on second language students' writing. Language Teaching, 39: 83-101.

Kessler, G. (2009) Student-initiated attention to form in wiki-based collaborative writing. Language learning \& Technology, 13(1): 79-95.

Lamb, B. (2004) Wide open spaces: Wiki, ready or not. Educause Review, 39(5): 36-48.

Lankshear, C. and Knobel, M. (2003) New Literacies. Changing Knowledge and Classroom Learning. Buckingham, UK: Open University Press.

Lantolf, J. and Thorne, S. (2006) Sociocultural Theory and the Genesis of Second Language Development. Oxford: Oxford University Press.

Lee, I. (2008) Ten mismatches between teachers' beliefs and written feedback practice. ELT Journal, 63(1): 13-22.

Leuf, B. and Cunningham, W. (2001) The wiki way: Quick collaboration on the web. Boston, MA: Addison-Wesley Longman Publishing Co.

Liu, J. and Sadler, R. (2003) The effect and affect of peer review in electronic versus traditional modes on L2 writing. Journal of English for Academic Purposes, 2(3): 193-227.

Lund, A. and Smørdal, O. (2006) Is There Space for the Teacher in a Wiki? In: Proceedings of the 2006 International Symposium on Wikis (WikiSym '06). Odense, Denmark: ACM Press, 27-46.

Lund, A. (2008) Wikis: a collective approach to language production. ReCALL, 20(1): 35-54.

Mak, B. and Coniam, D. (2008) Using wikis to enhance and develop writing skills among secondary school students in Hong Kong. System, 36: 437-455.

Prensky, M. (2005) Learning in the Digital Age. Educational Leadership, 63(4): 8-13.

Rollinson, P. (2005) Using peer feedback in the ESL writing class. ELT Journal, 59(1): 23-30.

Säljö, R. (2005) Lärande i praktiken. Ett sociokulturellt perspektiv [Learning in Practice: A sociocultural perspective]. Stockholm: Norstedts Akademiska Förlag.

Sotillo, S. (2002) Constructivist and Collaborative Learning in a Wireless Environment. TESOL Journal, 11(3): 16-20.

Warschauer, M. (2005) Socio-cultural perspectives on CALL. In: Egbert, J. and Petrie, G. M. (eds.) CALL Research Perspectives. Mahwah, NJ: Lawrence Erlbaum, 41-51. 